\title{
Frequency of unexpected antibody and consideration during transfusion
}

\author{
Ki-Ho Ko ${ }^{1}$, Byung-Hoon Yoo ${ }^{1}$, Kye-Min Kim , Woo-Yong Lee ${ }^{1}$, Jun-Heum Yon ${ }^{1}$, Ki-Hyuk Hong ${ }^{1}$, and \\ Tae-Hee $\operatorname{Han}^{2}$ \\ Departments of ${ }^{1}$ Anesthesiology and Pain Medicine, ${ }^{2}$ Laboratory Medicine, Sanggye Paik Hospital, College of Medicine, \\ Inje University, Seoul, Korea
}

Background: In this retrospective study, we measured the frequency of unexpected antibodies in the blood. Specific considerations for preoperative preparations were kept in mind for the patients undergoing surgery positive for these antibodies.

Methods: After reviewing the results of antibody screening tests lasted for 2 years, the frequency of unexpected antibodies was determined. Surgical patients who were positive for unexpected antibodies were selected and divided into two groups based on their potential need for an intra-operative transfusion (groups with high versus low possibility of transfusion). Blood for the high possibility group was prepared before surgery. For the low possibility group for which preoperative blood preparation was not performed, cases of this group were reviewed whether a blood preparation was delayed or not in case of transfusion.

Results: Among a total 22,463 cases, 340 (1.52\%) had positive results for antibody screening tests. Among the 243 patients who were positive for unexpected antibodies, Lewis, Rh, Xga, and mixed antibodies were found in 85, 25, five, and eight cases, respectively. Out of 243 patients, 117 patients, specificities of the unexpected antibodies were not determined and 125 (51.4\%) had a history of pregnancy and delivery, and 49 (20.2\%) had a history of transfusion. In the low probability group, transfusions were administered for nine patients; transfusion was delayed for two patients due to difficulties with obtaining matched blood.

Conclusions: Patients with unexpected blood antibodies may be at increased risk for delayed transfusion. For rapid transfusion, it might be helpful to keep a record about blood antibodies and introduce a notification system such as medical alert cards. Preoperative blood preparation is needed for timely intraoperative transfusion. (Korean J Anesthesiol 2012; 62: 412-417)

Key Words: Antibodies, Blood transfusion, Complications.

Received: July 11, 2011. Revised: September 6, 2011. Accepted: September 9, 2011.

Corresponding author: Byung-Hoon Yoo, M.D., Ph.D., Department of Anesthesiology and Pain Medicine, Sanggye Paik Hospital, College of Medicine, Inje University, 761-1, Sanggye 7-dong, Nowon-gu, Seoul 139-707, Korea. Tel: 82-2-950-1173, Fax: 82-2-950-1323, E-mail: twowind@paik.ac.kr (c) This is an open-access article distributed under the terms of the Creative Commons Attribution Non-Commercial License (http:// creativecommons.org/licenses/by-nc/3.0/), which permits unrestricted non-commercial use, distribution, and reproduction in any medium, provided the original work is properly cited. 


\section{Introduction}

One of the most important issues for patient care during anesthesia is managing bleeding. For this, it is important to know the patient's pre-operative hemoglobin levels and coagulation function, as well as the status of important organs. Based on this information, the appropriate amounts of fluids and blood to be administered during surgery can be determined. When managing bleeding, the first concern is to reduce the amount of bleeding during surgery while the second concern is to mitigate complications associated with transfusion [1]. For the latter, it is important to be aware of the existence and specific characteristics of unexpected antibodies identified in the patient.

Unexpected antibodies are sometimes referred to as irregular antibodies because their existence and type are unknown before conducting a antibody screening test. This category of antibodies includes most blood type antibodies excluding $\mathrm{ABO}$ and some P blood type antibodies [2]. Depending on the type of antibody, some develop naturally in patients but most unexpected antibodies are formed as part of the immune response after exposure to foreign antigens during pregnancy or transfusion. These antibodies can cause acute and delayed hemolytic transfusion reactions; there are many reports of such cases $[3,4]$. It is therefore important to conduct test to screen for and identify unexpected antibodies before transfusion.

For patients who require transfusions, it is vital to conduct pre-operative testing to minimize complications and improve transfusion safety. For these reasons, it is essential to know the frequency and distribution of unexpected antibodies among South Koreans for prompt and safe transfusion [2]. The purpose of this study was to examine the frequency and type of unexpected antibodies found by antibody screenings conducted in our hospital from 2009 to 2010. In addition, we examined problems and issues associated with transfusion when unanticipated bleeding occurs in patients who are positive for unexpected antibodies.

\section{Materials and Methods}

In Sanggye Paik hospital, 22,436 tests to screen for un- expected antibodies were conducted from 2009 to 2010. Data were examined to calculate the frequency of unexpected antibodies. The unexpected antibody test results for 243 surgical patients who were positive in the screening were then examined. Information about the gender, pregnancy history, parity, and transfusion history of these patients was collected from the electronic medical records of the hospital. The 243 surgical patients who were positive for unexpected antibodies were divided into a high possibility group and a low possibility group for transfusion based on the likelihood of $500 \mathrm{ml}$ of predicted blood loss. Additionally, the availability of matched blood before surgery and whether an actual transfusion occurred were determined.

\section{Unexpected antibody screening test}

A quantitative test was performed using the Ortho BioVue microcolumn agglutination system (Ortho-Clinical Diagnostics, Raritan, NJ, USA). The test was performed according to the manufacturer's instructions.

\section{Unexpected antibody identification test}

When the screening test results were positive, an unexpected antibody identification test was performed with a microcolumn agglutination system using ID-Diapanel I, II (DiaMed, Murten, Switzerland) and LISS/Coombs cards (DiaMed).

\section{Results}

\section{Frequency of unexpected antibodies}

Among a total of 22,436 cases for which unexpected antibody screening tests were conducted, 340 (1.52\%) were positive. The number of positive patients according to year was 116 (1.13\%) for 2009 and 127 (1.04\%) for 2010. The proportions of positive screening results were similar despite an increase in the number of subjects (Table 1). Among the patients positive for unexpected antibodies, 243 were patients underwent surgery. The gender, parity history, and transfusion history of these individuals are shown in Table 2.

Table 1. Frequency of Unexpected Antibodies

\begin{tabular}{cccc}
\hline Year & $\begin{array}{c}\text { No. of } \\
\text { patients }\end{array}$ & $\begin{array}{c}\text { No. of patient with } \\
\text { unexpected antibodies }\end{array}$ & $\begin{array}{c}\text { No. of patients with unexpected } \\
\text { antibodies undergoing surgery }\end{array}$ \\
\hline 2009 & 10,267 & $129(1.26 \%)$ & $116(1.13 \%)$ \\
2010 & 12,169 & $211(1.73 \%)$ & $127(1.04 \%)$ \\
Total & 22,436 & $340(1.52 \%)$ & $243(1.08 \%)$ \\
\hline
\end{tabular}

Data are expressed as the number (percentage). 
Table 2. Characteristics of 243 Patients with Unexpected Antibodies who Underwent Surgery

\begin{tabular}{llcc}
\hline \multicolumn{1}{c}{ Characteristics } & \multicolumn{3}{c}{$\begin{array}{c}\text { No. of } \\
\text { patients }\end{array}$} \\
\hline \multirow{2}{*}{ Gender } & Male & 102 & 41.96 \\
History of pregnancy and delivery & Female & 141 & 58.04 \\
& Positive & 125 & 51.44 \\
History of transfusion & Negative & 118 & 48.56 \\
& Positive & 49 & 20.16 \\
& Negative & 194 & 79.84 \\
\hline
\end{tabular}

\section{Type and distribution of unexpected antibodies}

The results of the unexpected antibody identification tests conducted for the 243 surgical patients showed that the Lewis antibody had the highest frequency $(30.44 \%)$ followed by antiLe antibody (21.81\%). The frequencies of Rh antibodies were $7.41 \%$ for anti-E, $2.47 \%$ for anti-D, and $0.41 \%$ for anti-C. Two or more antibodies were found together in $3.29 \%$ of cases; one person had only autoantibodies while another individual had both autoantibodies and alloantibodies. Unexpected antibodies were not accurately identified in $48.14 \%$ of the cases (Table 3 ).

\section{Availability of matched blood and actual performance of transfusion according to predicted blood loss during surgery}

Out of the 243 surgical patients who were positive for unexpected antibodies, 43 (17.7\%) were in the high possibility group and 200 (82.3\%) were in the low possibility group. In the high possibility group, there were no cases for which matched blood was not prepared before surgery. Matched blood was not prepared for the low possibility group before surgery; situations that required transfusion occurred for nine patients in this group (Table 4). For seven cases, there were no difficulties with securing matched blood, but difficulties in securing matched blood were encountered for the other two cases. One of these cases was a patient with no underlying diseases other than anemia with an $\mathrm{Hb}$ of $8.0 \mathrm{~g} / \mathrm{dl}$ before surgery that decreased to $7.0 \mathrm{~g} / \mathrm{dl}$ during surgery. Matched blood could not be obtained for this individual, so surgery continued with the patient receiving only fluid therapy. Since there was no continuous blood loss, surgery was completed without transfusion. After the completion of surgery, an $\mathrm{Hb}$ of $7.0 \mathrm{~g} / \mathrm{dl}$ was maintained, and there were no major changes in vital signs and no specific complications.

The other patient did not have any underlying diseases, but had received a transfusion of 11 units of packed red blood cells during an abdominal operation approximately 2 months prior to our study. At the time of transfusion, the antibody screening
Table 3. Classification of Detected Unexpected Antibodies in 243 Patient who Underwent Surgery

\begin{tabular}{|c|c|c|}
\hline Antibody specificity & $\begin{array}{c}\text { No. of } \\
\text { patients }\end{array}$ & $\%$ \\
\hline \multicolumn{3}{|l|}{$\mathrm{Rh}$} \\
\hline Anti-C & 1 & 0.41 \\
\hline Anti-D & 6 & 2.47 \\
\hline Anti-E & 18 & 7.41 \\
\hline \multicolumn{3}{|l|}{ Lewis } \\
\hline Anti-Le a & 53 & 21.81 \\
\hline Anti-Le b & 21 & 8.64 \\
\hline \multicolumn{3}{|l|}{ MNSs } \\
\hline Anti-M & 11 & 4.53 \\
\hline \multicolumn{3}{|l|}{ Xga } \\
\hline Anti-Xga & 1 & 0.41 \\
\hline \multicolumn{3}{|l|}{ Others } \\
\hline Anti-P1 & 4 & 1.65 \\
\hline \multicolumn{3}{|l|}{ Mixed antibodies } \\
\hline Anti-Le a + Le b & 3 & 1.23 \\
\hline Anti Le a + ?* & 4 & 1.65 \\
\hline Anti E + ?* & 1 & 0.41 \\
\hline \multicolumn{3}{|l|}{ Combined with an autoantibody } \\
\hline Autoantibody & 1 & 0.41 \\
\hline Autoantibody and non-specific antibody & 1 & 0.41 \\
\hline \multicolumn{3}{|l|}{ Unidentified } \\
\hline Non-specific antibody & 108 & 44.44 \\
\hline Unidentified (all positive) & 9 & 3.70 \\
\hline Total & 243 & 100 \\
\hline
\end{tabular}

*unable to identify antibody.

Table 4. Number of Patients Who Received Intraoperative Transfusions

\begin{tabular}{lcc}
\hline & $\begin{array}{c}\text { High probability of } \\
\text { transfusion group }\end{array}$ & $\begin{array}{c}\text { Low probability of } \\
\text { transfusion group }\end{array}$ \\
\hline $\begin{array}{l}\text { No. of patients } \\
\text { Transfusion } \\
\text { Yes }\end{array}$ & 43 & 200 \\
No & $33(76.74 \%)$ & $9(4.5 \%)$ \\
\hline
\end{tabular}

Data are expressed as the number of patients or percentage.

test results were negative. The patient underwent abdominal surgery to treat an enterocutaneus fistula, and the operation protocol included Whipple's procedure. During the procedure, excessive bleeding occurred and packed red blood cells were ordered. However, the blood bank reported that matched blood was not available. As a result, the patient's Hb decreased to 4.7 $\mathrm{g} / \mathrm{dl}$, and total blood loss reached 3,000 $\mathrm{ml}$. After 3 hours and 30 minutes, 8 units of packed red blood cells that showed the weakest cross-matching reaction were obtained. Five of these units were transfused while the patient was carefully monitored for any transfusion-related complications. The procedure was completed without any problems and no specific complications developed after surgery.

The two cases mentioned above involved patients who received transfusions and were negative for unexpected antibodies. For both individuals, difficulties in securing matched blood during 
surgery were encountered. Thus, transfusion was delayed. Through additional screening performed after surgery, both patients were identified as positive for unexpected antibody. One was found to have both autoantibodies and alloantibodies while the other had only autoantibodies.

\section{Discussion}

It is generally known that there are large differences in the frequency and type of unexpected antibodies found during screening according to the research subjects, blood type, genotypic frequency, screening method, and ability of the decoder [5]. The frequency of unexpected antibodies is reported to be $1.35 \%$ in Denmark [6], $0.78 \%$ in Germany [7], and $0.3-2 \%$ in the USA [8,9]. In South Korea, the frequency of unexpected antibodies was reported to be $1.57 \%$ by Lee et al. [10], $0.51 \%$ by Park et al. [11], and $0.58 \%$ by Han et al. [12]. Without considering differences in research subjects, the mean frequency of positive results obtained for South Koreans based on the above research results is approximately $0.84 \%$. The high frequency reported by Lee et al. is thought to be related to the fact that approximately $96 \%$ of the research subjects in this study had undergone pregnancy and transfusion. The patients in our study also showed a high frequency of $1.52 \%$, which is thought to be due to their high rates of pregnancy, parity of the research subjects, and improvement in screening techniques.

If positive antibody screening results are obtained before transfusion, an antibody identification test is conducted to determine the antibody specificity. If the specificity of the antibody is identified, then the percentage of available blood that is negative for the relevant antibody is calculated. For example, if anti-E is found, it can be estimated that 1 out of 2 units of blood in South Korea will be negative for the antibody. If anti-e antibody is present, it can be estimated that 1 out of 10 units of blood will be negative for the antibody. If 3 units of blood are to be transfused, 6 or more units of ABO- and Rh-appropriate blood should be prepared for anti-E-positive patients, while 30 or more units of $\mathrm{ABO}$ - and Rh-appropriate blood should be prepared for anti-e-positive patients. Then, blood that is negative for the relevant antibody must be found by testing with commercialized antibody reagents. The negative blood is then cross-matched with the patient's serum, and if it is observed to be suitable, the blood is secured for transfusion [2]. Therefore, when excessive blood loss is anticipated during surgery, matched blood must be obtained before the operation for prompt and safe transfusion. For cases in which finding matched blood is difficult, such as ones involving individuals with anti-e antibodies, the amount of blood loss during surgery should be predicted for the preparation process.

Alloimmunization responses to red blood cell antigens occur when unexpected antibodies develop after exposure to red blood cell antigens that are foreign to the patient [2]. This can occur due to transfusion or pregnancy. Additionally, antibody formation can occur due to an anamnestic response when there is repeated exposure to the same red blood cell antigen. Antibodies are not formed weeks or even months after initial exposure to foreign red blood cell antigens. Depending on the repeated exposure to the antigen, antibodies can rapidly appear within 48-72 hours after transfusion and reach a maximum $7-10$ days later $[5,13]$. Among the types of alloimmunization responses, a hemolytic response to the newly formed antibody is classified as a delayed hemolytic reaction while an absence of hemolysis is classified as a delayed serologic reaction.

According to existing international report, the rate of detection of unexpected antibodies after transfusion in healthy people is approximately $1-1.6 \%$ [13]. Retrospective analysis of reports from Korea medical institutions showed that the detection rate of unexpected antibodies is about $0.46-1.5 \%$ [10,12,14-19]. Park et al. [20] determined that the rate of unexpected antibodies after transfusion was $0.89 \% .0 .81 \%$ of unexpected antibodynegative patients became positive for these antibodies following transfusion while $3.38 \%$ of unexpected antibody-positive patients were found to develop more of these antibodies after transfusion.

The Lewis antibody, which was the most frequently identified antibody in our study, is an IgM antibody which cannot pass through the placenta and so is unrelated to hemolytic disorders in newborns. This antibody, which is detected through direct agglutination, can occasionally cause hemolytic complications associated with transfusion and is frequently found in expectant mothers with no great clinical significance [19]. However, Han et al. [21] determined that anti-Le a, which is a type of Lewis antibody, causes delayed hemolytic reactions. The facts that Anti-Le a antibodies are mostly formed not from immune response but spontaneously, and that the patient in their case had no history of pregnancy or transfusion were cited as the reasons for their conclusion.

Anti-K, which is has been found at high frequencies in countries other than South Korea, is a significant alloantibody which can cause hemolytic disease of newborns or serious transfusion complications [22]. Formation of this antibody is mainly due to transfusion or pregnancy, and although its frequency is reported to be low among South Koreans [23] and it was not identified in our study. The reason for this finding is that despite the consistency red blood cell antigen immunogenicity, the antigen cultivation rate can vary significantly according to ethnicity. For example, $9.0 \%$ of Caucasians are positive for $\mathrm{K}$ antigen, while only $\mathbf{0 . 5 \%}$ of South Koreans are positive for this antigen; thus, the formation of anti-K antibody following transfusion or pregnancy in South Koreans is relatively rare [2]. 
Unexpected antibodies that exist at low titers may not be detected by pre-transfusion tests, but may cause unexpected hemolytic responses due to the transfusion of red blood cells that react with the antibodies. In addition, antibody titers can increase due to secondary immune responses, which can cause serious hemolytic transfusion complications during a subsequent transfusion. To reduce the occurrence of delayed hemolytic reactions, blood samples should be collected and tested every 72 hours for patients who need multiple transfusions, or a highly sensitive testing method should be used for the pre-transfusion test [24].

The decision of administer transfusions to patients with autoimmune hemolytic anemia are made according to the patient's response to hemolysis, the cause of immunohemolytic anemia, and the type of antibodies that lead to this condition. Patients with no history of pregnancy or transfusion are unlikely to have alloantibodies other than autoantibodies, and so suitable blood for transfusion can be selected without conducting an autoantibody absorption test (ZZAP test). However, judging from the discovery of alloantibodies in 209 out of 647 patients $(32.30 \%)$ with autoimmune hemolytic anemia [25], the co-existence of alloantibodies should be kept in mind when selecting matched blood for patients who have received multiple transfusions or females who have given birth more than once [2]. In our study, a ZZAP test [26] was performed on two patients who had a history of transfusion and were positive for unexpected antibodies. This confirmed the co-existence of alloantibodies and autoantibodies. Only autoantibodies were identified in one of the patients while the other had both alloantibodies and autoantibodies.

It is difficult to differentiate autoantibodies from alloantibodies because most red blood cells and autoantibodies react. The effort to find matched blood is necessary when alloantibodies and autoantibodies co-exist, but there is almost no need to find matched blood when only autoantibodies exist [2]. Hence, most blood banks transfuse red blood cells that show the lowest degree of response in cross-matching tests for patients with only autoantibodies. For individuals with both auto- and alloantibodies, red blood cells negative for the relevant antigen that show the smallest response are transfused. In the latter case, it can be difficult to promptly find matched blood, so the anesthesiologist must identify the existence of unexpected antibodies before surgery, and ensure prompt and safe transfusion through close cooperation with the surgeon and blood bank.

The main purposes of transfusion are to enhance oxygen transportation, maintain appropriate blood volume, and provide coagulation factors. Among these factors, enhancement of oxygen transportation is the most important. Timing the administration of homologous blood is usually determined based on hemoglobin or hematocrit levels. Factors involved in this judgment include the patient's cardiovascular state, age, anticipated additional blood loss, arterial blood oxygenation, $\mathrm{PO}_{2}$ in mixed venous blood, cardiac output, and total blood volume [27]. Healthy adults do not require transfusion until $\mathrm{Hb}$ decreases to $6 \mathrm{~g} / \mathrm{dl}$, but patients with underlying conditions such as coronary or chronic lung diseases need transfusions even when $\mathrm{Hb}$ is as high as $10 \mathrm{~g} / \mathrm{dl}[28]$.

The two patients in our study whose transfusions were delayed were healthy individuals with no specific underlying diseases. However, transfusions were ordered because their clinical status indicated the need for transfusion. Difficulties with securing matched blood based on cross-matching were encountered. As a result, one of the patients received a transfusion of packed red blood cells that showed the least cross-matching response. This individual recovered without developing transfusion-associated complications or other effects. Although transfusion was delayed in both of these patients due to difficulties in securing matched blood, no specific complications developed because the patients were young and had no underlying diseases. However, patients with ischemic heart conditions such as coronary, lung, or cerebrovascular diseases are highly likely to develop complications due to delays in transfusion.

For patients positive for unexpected antibodies, blood that does not have antigens which can cause an anamnestic response should be selected and transfused [29]. Some medical institutions issue medical alert cards containing this information for patients to present when hospitalized or undergoing transfusion [5]. Clinically significant alloantibodies already formed in the blood can cause hemolytic reactions during transfusions or pregnancies, so caution is necessary. Therefore, medical institutions should maintain permanent records of patients who produced unexpected antibodies due to an alloimmunization response to ensure safe and prompt transfusion. Issuing medical alert cards containing this information, which can be presented at other medical institutions, should also be introduced.

Fortunately, antibody formation due to anamnestic responses generally causes only delayed serologic reactions $[5,13]$. In some patients, however, high antibody titers and large red blood cell transfusion volumes can induce hemolytic reactions. The reported frequency of hemolysis is one case in 5,000-11,000 transfusions, which represents $0.05-0.07 \%$ of patients who receive transfusions [5]. Therefore, when there is a sudden need for transfusion due to acute bleeding during surgery, the anesthesiologist should consider the possibility of complications and risks from transfusion delays. This is particularly important for patients with unexpected antibodies for whom there could be difficulties in finding matched blood for transfusion. 


\section{Acknowledgements}

This work was supported by 2005 Inje University research grant.

\section{References}

1. Lee SJ, Lee KY, Seo BS, Nam YT. Effects of acute normovolemic hemodilution under induced hypotension on blood saving and homologous transfusion in orthognathic two jaw surgery. Korean J Anesthesiol 2004; 46: 690-5.

2. Han KS, Park MH, Kim SI. Transfusion medicine. 3rd ed. Seoul, Korea Medical Publisher. 2006, pp 153-287.

3. Lee HH, Kim TY, Park MJ, Sung TJ. A case of hemolytic disease of the newborn caused by anti-c and anti-E antibody requiring multiple exchange transfusions. Korean J Perinatol 2009; 20: 65-8.

4. Lee JH, Lee SG, Bae IC, Baek EJ, Kim S, Kim HO. A case of hemolytic transfusion reaction in a patient with anti-E, anti-M, anti-Jkb, and Anti-Lea. Korean J Blood Transfus 2008; 19: 67-73.

5. Brecher ME. Technical manual. 14th ed. Bethesda, Maryland, American Association of Blood Banks. 2002, pp 315-97.

6. Skov F, Ericksen M, Hagerup L. Distribution of the ABO, MNS, $\mathrm{P}$, Rhesus, Lutheran, Kell, Lewis and Duffy blood groups and frequency of irregular red cell antibodies in a population of Danes aged fifty years and a population of Danes aged seventy years. From the Glostrup population studies. Acta Pathol Microbiol Scand B Microbiol Immunol 1970; 78: 553-9.

7. Spielmann W, Seidl S. Prevalence of irregular cell antibodies and their significance in blood transfusion and antenatal care. Vox Sang 1974; 26: 551-9.

8. Giblett ER. Blood group allantibodies: an assessment of some laboratory practices. Transfusion 1977; 17: 299-308.

9. Boral LI, Henry JB. The type and screen: a safe alternative and supplement in selected surgical procedures. Transfusion 1977; 17: 163-8.

10. Lee MH, Cho HI, Kim SI. A study on blood group antibodies in the Korean. Korean J Hematol 1986; 21: 243-56.

11. Park MH, Kim SH, Song WH, Cho HI. Screening of irregular red cell antibodies by microplate method in transfusion candidates. Korean J Clin Pathol 1986; 6: 473-81.

12. Han KS, Oh WI, Park MH, Kim EC, Kim SI. Irregular blood group antibodies in Korean. Korean J Hematol 1989; 24: 145-53.

13. Heddle NM, Soutar RL, O'Hoski PL, Singer J, McBride JA, Ali MA, et al. A prospective study to determine the frequency and clinical significance of alloimmunization post-transfusion. $\mathrm{Br} \mathrm{J}$ Haematol 1995; 91: 1000-5
14. Kim HO, Won DI, Kwon OH. The frequencies of unexpected antibodies in transfusion candidates and selection of cross-matching method. Korean J Blood Transfus 1993; 4: 35-41.

15. Song DH, Moon IS, Hong SJ, Park JH, Kim JK, Jeon DS. Frequency and distribution of unexpected antibodies of Koreans. Korean J Blood Transfus 1998; 9: 191-200.

16. Shin JW, Jeong SH, Nahm CH, Kim HO, Kwon OH. The direct antiglobulin test and antibody screening test based on the antiglobulin gel technique. Korean J Clin Pathol 1996; 16: 411-8.

17. Lee WH, Kim SY, Kim HO. The incidence of unexpected antibodies in transfusion candidates. Korean J Blood Transfus 2000; 11: 99-103.

18. Jung TK, Lee NY, Bae HG, Kwon EH, Park SH, Suh JS. Unexpected antibody positivity with the use of the LISS/Coombs gel test. Korean J Clin Pathol 2001; 21: 422-5.

19. Kim BS, Kim HO, Song KS, Lee SY. Frequency of irregular antibodies detected by type and screen procedure. Korean J Blood Transfus 1990; 1: 47-50.

20. Park TS, Chang CL, Chung JS, Cho H, Lee EY, Son HC, et al. The frequency and clinical significance of delayed serological transfusion reactions in Korean population. Korean J Blood Transfus $2005 ; 16: 20-31$.

21. Han KS, Cho HI, Kim SI. A study on the hemolytic transfusion reactions due to irregular antibodies. Korean J Hematol 1989; 24: 2733.

22. Schonewille H, Haak HL, van Zijl AM. Alloimmunization after blood transfusion in patients with hematologic and oncologic diseases. Transfusion 1999; 39: 763-71.

23. Lee HY, Joo SY, Shin S, Sung SJ, Roh EY, Yoon JH, et al. A comparison of two microcolumn agglutination systems for red cell antibody screening and identification. Korean J Blood Transfus 2008; 19: 1328.

24. Pineda AA, Vamvakas EC, Gorden LD, Winters JL, Moore SB. Trends in the incidence of delayed hemolytic and delayed serologic transfusion reactions. Transfusion 1999; 39: 1097-103.

25. Branch DR, Petz LD. Detecting alloantibodies in patients with autoantibodies. Transfusion 1999; 39: 6-10.

26. Branch DR, Petz LD. A new reagent (ZZAP) having multiple applications in immunohematology. Am J Clin Pathol 1982; 78: 161-7.

27. Miller RD. Transfusion therapy. In: Miller's Anesthesia. 6th ed. Editered by Miller RD: Philadelphia, Churchill Livingstone. 2009, pp 1739-66.

28. Ronald D. Miller. Blood therapy. In: Basic of Anesthesia. 5th ed. Editered by Robert K. Stoelting: Philadelphia, Churchil Livingstone. 2007, pp 355-62

29. Park TS, Hwang SY, Kim HH, Kim YS, Park SK, Lee EY, et al . Transfusion Therapy in a Patient with Hemolytic Transfusion Reaction due to Anti-Jka. Korean J Blood Transfus 2003; 14: 60-4. 